\title{
Identification alpha-2-HS-glycoprotein precursor and tubulin beta chain as serology diagnosis biomarker of colorectal cancer
}

Nai-Jun Fan ${ }^{1,2}$, Rui Kang ${ }^{1}$, Xue-Yan Ge1, Ming Lii, Yan Liư ${ }^{4}$, Hong-Mei Chen ${ }^{5}$ and Chun-Fang Gao ${ }^{\text {* }}$

\begin{abstract}
Background: Colorectal cancer (CRC) remains a major worldwide cause of cancer-related morbidity and mortality largely due to the insidious onset of the disease. The current clinical procedures utilized for disease diagnosis are invasive, unpleasant, and inconvenient. Hence, the need for simple blood tests that could be used for the early detection is crucial for its ultimate control and prevention.

Methods: The present work is a case-control study focused on proteomic analysis of serum of healthy volunteers and CRC patients by the ClinProt profiling technology based on mass spectrometry. This approach allowed to identifying a pattern of proteins/peptides able to differentiate the studied populations. Moreover, some of peptides differentially expressed in the serum of patients as compared to healthy volunteers were identified by LTQ Orbitrap XL.

Results: A Quick Classifier Algorithm was used to construct the peptidome patterns (m/z 1208, 1467, 1505, 1618,1656 and 4215 ) for the identification of CRC from healthy volunteers with accuracy close to 100\% (>CEA, $P<0.05$ ). Peaks at $\mathrm{m} / \mathrm{z} 1505$ and 1618 were identified as alpha-2-HS-glycoprotein precursor and tubulin beta chain, respectively.
\end{abstract}

Conclusions: Alpha-2-HS-glycoprotein precursor and tubulin beta chain could be involved in the pathogenesis of CRC and perform as potential serology diagnosis biomarker.

Virtual slides: The virtual slide(s) for this article can be found here: http://www.diagnosticpathology.diagnomx. eu/vs/4796578761089186.

Keywords: Colorectal neoplasms, Diagnosis, Biological markers, Proteomics, Alpha-2-HS-glycoprotein, Tubulin beta chain

\section{Introduction}

Colorectal cancer $(\mathrm{CRC})$ is the third most commonly diagnosed cancer in males and the second in females, with over 1.2 million new cancer cases and 0.61 million deaths estimated to have occurred in 2008. This is due to the insidious onset of the disease largely [1]. More than $60 \%$ of patients with CRC are either locally or distantly invasive at diagnosis, restricting treatment options and reducing survival rates, whereas the 5-year survival rate is extremely favorable if detected at an early stage

\footnotetext{
* Correspondence: chunfanggao@126.com

'Institute of Anal-colorectal Surgery, No.150 Central Hospital of PLA, Luoyang, RP China

Full list of author information is available at the end of the article
}

and treated early, while the tumors were still localized [2-5]. However, the early diagnosis rate is still comparatively low as the current clinical procedures utilized for CRC diagnosis are either invasive, unpleasant, inconvenient or low sensitivity [6,7]. Hence, the need for simple blood tests that could be used for the early detection, which emerging with potential to improve screening effectiveness and userfriendliness, is crucial for its ultimate control and prevention.

Biomarkers are important tools for cancer detection and monitoring. They serve as hallmarks for the physiological status of a cell at a given time and change during the disease process, including CRC [8-10]. Many existing cancer biomarkers are glycoproteins, such as carcinoembryonic 
antigen (CEA) in CRC. Despite of remaining the most widely used serum biomarker, CEA is precluded its use for the early detection of CRC due to poor sensitivity and specificity [11]. The emerging field of clinical proteomics is especially well suited to the discovery and implementation of potential biomarkers, as body fluids are an cellular and protein-rich information reservoir that contains traces of what the blood has encountered during its circulation through the body [12]. Serum proteome analysis has the potential to facilitate disease diagnosis and therapeutic monitoring, because serum is more easily accessible and widely collected sample, which contains $>10,000$ different proteins and peptides [13-17]. A novel technology platform, called ClinProt (Bruker Daltonics, Ettlingen, Germany), comprising a magnetic bead (MB) based sample separation, matrix-assisted laser desorption/ ionization time of flight mass spectrometry (MALDI-TOF MS) for protein/peptide profiling acquisition, and a bioinformatics package for inspection and comparison of data sets to create "disease-specific" protein/peptide patterns models, could serve as a powerful tool for the diagnosis of cancer $[15,16,18-23]$. Previously, our group quantified 61 dysregulation proteins/peptides in CRC, including 49 upregulated and 12 down-regulated proteins/peptides using this technology platform [24]. However, the dysregulation proteins/peptides were not identified. LTQ Orbitrap XL MS/MS (Michrom Bioresources, Auburn, USA) shows great potential for protein identification [25]. Therefore, we applied the combination of MB, MALDI-TOF MS and LTQ Orbitrap XL MS/MS for globally analyze and identification of the serum biomarkers associating with CRC.

\section{Materials and methods}

\section{Reagents and instruments}

The AutoFlex III MALDI-TOF MS, MTP 384 target plate polished steel, $\alpha$-cyano-hydroxycinnamic (CHCA), MB-WCX kit and peptide calibration standard were purchased from Bruker Daltonics (Leipzig, Germany). Trifluoroacetic acid (TFA) was purchased from Alfa Aesar (Ward Hill, MA, USA). Acetonitrile (ACN) was acquired from Sigma (St. Louis, MO, USA). Diagnostic Kit of Carcinoembryonic antigen (CEA) (ELISA) was acquired from Roche Diagnostics $\mathrm{GmbH}$ (Sandhofer Strasse, Germany). Nano Aquity UPLC was acquired from Waters Corporation (Milford, USA) and LTQ Orbitrap XL MS/MS was acquired from Michrom Bioresources (Auburn, USA).

Patients, health volunteers and sample collection

Valid records of No.150 Central Hospital of the People's Liberation Army (PLA) Cancer Center were searched for patients with a histological diagnosis of CRC whose serum samples had been obtained from January of 2011 to December of 2012. Health volunteers come from the healthy physical examination in No.150 Central Hospital of PLA January of 2011 to December of 2012. Seventy health volunteers (blood donor volunteers) and 72 CRC patients were enrolled with the permission of the Local Ethical Commission, and blood was collected after informed consent from the patients. Enteroscopy were performed in all health subjects to exclude the presence of incidental colon and rectum mass. CRC patients underwent clinical staging, surgical excision of the lesion, and were followed up. Pathologic samples were classified according to the 2004 tumor-node-metastasis (TNM) stage classification [26]. The clinical characteristics of CRC patients were shown in Table 1.

Serum samples were prepared by collecting blood in a vacuum tube and allowing it to clot for 30 minutes at room temperature. About $1 \mathrm{~mL}$ of serum was obtained after centrifugation at $2000 \mathrm{rpm}$ for 10 minutes, and it was stored in small aliquots at $-80^{\circ} \mathrm{C}$ until analysis.

\section{Study design}

The data set including 70 healthy volunteers and 72 CRC patients was randomly split into model construction group and external validation group. The model construction group (including 35 health volunteers and 36 CRC patients) was used for the identification of signals related to proteins/peptides expressed differentially in CRC patients compared with health volunteers and diagnosis patterns recognition. The external validation group (including 35 health volunteers and 36 CRC patients) was used for the independent validation of the diagnosis patterns blindly. The accuracy of the peptide model was compared with that of CEA.

Table 1 Clinical characteristics of colorectal cancer patients recruited in model construction group and external validation group

\begin{tabular}{lccc}
\hline $\begin{array}{l}\text { Clinical } \\
\text { characteristics }\end{array}$ & $\begin{array}{c}\text { Model } \\
\text { construction } \\
\text { group } \\
(\mathbf{n}=\mathbf{3 6})\end{array}$ & $\begin{array}{c}\text { Evaluation } \\
\text { group }\end{array}$ & P-value \\
\hline Gender: male/female & $19 / 17$ & $19 / 17$ & $1.000^{\S}$ \\
Age (years, $\bar{X} \pm S D)$ & $63.58 \pm 10.02$ & $61.19 \pm 11.48$ & $0.875^{\#}$ \\
TNM stage & 6 & 5 & 0.629 \\
& 17 & 16 & \\
& 12 & 13 & $0.629^{\S}$ \\
Tumor localization & 1 & 2 & \\
Colon & 15 & 13 & \\
Rectum & 21 & 23 &
\end{tabular}

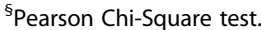

\#Independent-Sample T Test. 
The gender ratio (male/female) of health volunteers and CRC patients was 1.12 and 1.18 , respectively. The mean age (years) of health volunteers and CRC patients was $58.94 \pm 8.32$ and $62.43 \pm 9.37$, respectively. The difference of age and gender of health volunteers in model construction group and external validation group were not significantly. No significant differences were observed for TNM stage of CRC between model construction group and external evaluation group (Table 1).

\section{Sample purification}

We used MB-WCX for proteins/peptides separation of samples following the standard protocol by the manufacturer [27]. Briefly, the sera and ClinProt Kit were left at room temperature for $2 \mathrm{~h}$ for serum protein fractionation, $10 \mu \mathrm{L}$ of WCX-MB binding solution and $10 \mu \mathrm{L}$ of WCX-beads were combined in a $0.5 \mathrm{~mL}$ microfuge tube after thoroughly vortexing both reagents. Then, $5 \mu \mathrm{L}$ of serum sample was added to the microfuge tube and mixed by pipetting up and down. The samples were then were then placed in a magnetic bead separator (MBS) where the beads were pulled to the side by magnetic force, allowing for the supernatant to be removed and discarded. After three washes with MB-WCX washing solution, the supernatant was removed and the beads remained in place. $5 \mu \mathrm{L}$ of WCX-MB elution buffer was added to disperse beads in tubes by pipetting up and down. Then the beads were pulled to the side and a fraction of the eluate was transferred to another tube. $5 \mu \mathrm{L}$ WCX-MB stabilization solutions were added to the collected supernatant, mixing intensively by pipetting up and down, the mixture was then ready for spotting onto MALDI-TOF MS targets and measurement. Finally, prior to the MALDI-TOF MS analysis, we prepared targets by spotting $1 \mu \mathrm{L}$ of the proteome fraction on the polished steel target (Bruker Daltonics ). After air drying, $1 \mu \mathrm{L}$ of $3 \mathrm{mg} / \mathrm{mL}$ CHCA in 50\% ACN and 50\% Milli-Q with $2 \%$ TFA was applied onto each spot, and the target was air dried again (co-crystallization). The peptide calibration standard $(1 \mathrm{pmol} / \mu \mathrm{L}$ peptide mixture) was applied for calibrating the machine.

\section{Mass spectrometry analysis}

For proteome analysis, we used a linear Autoflex III MALDI-TOF-MS with the following setting: ion source 1, $20.00 \mathrm{kV}$; ion source 2, $18.60 \mathrm{kV}$; lens, $6.60 \mathrm{kV}$; pulsed ion extraction, $120 \mathrm{~ns}$; Ionization was achieved by irradiation with a crystal laser operating at $200.0 \mathrm{~Hz}$. For matrix suppression, we used a high gating factor with signal suppression up to $600 \mathrm{Da}$. Mass spectrum were detected using linear positive mode. Mass calibration was performed with the calibration mixture of peptides and proteins in the mass range of 1 000-20 $000 \mathrm{Da}$. We measured three MALDI preparations (MALDI spots) for each MB fraction. For each MALDI spot, 1600 spectrum were acquired (200 laser shots at 8 different spot positions). Spectrum were collected automatically using the Autoflex Analysis software (Bruker Daltonik) for fuzzy controlled adjustment of critical instrument settings to generate raw data of optimized quality.

The criteria for protein mass peak detection $(\mathrm{m} / \mathrm{z})$ were as follows: signal-to-noise ratio $(\mathrm{S} / \mathrm{N})>5$, a $2-\mathrm{Da}$ peak width filter, and a maximum peak number of 200 . The intensities of the peaks of interest were normalized with the peak intensity of an ACTH internal standard. More than $10 \%$ of the molecular weight was sieved in simultaneous samples, with the discrepancy of identical spinnacle in different samples $<0.3 \%$ after removal of the initial data noise.

\section{Bioinformatics and statistical analysis}

The ClinProt Tools software 2.2 (Bruker Daltonik) was used for analysis of all serum sample data derived from either patients or normal controls. Data analysis began with raw data pretreatment, including baseline subtraction of spectrum, normalization of a set of spectrum, internal peak alignment using prominent peaks, and a peak picking procedure. The pretreated data were then used for visualization and statistical analysis in ClinProt Tools. Statistically significant different quantity of peptides was determined by means of Wilcoxon test. The significance was set at $\mathrm{p}<0.05$. Class prediction model was set up by GA. A classify proteins/peptides patterns was constructed. To determine the accuracy of the class prediction, firstly, a cross-validation was implemented. Twenty percent of model construction group were randomly selected sample as a test set, and the rest samples were taken as a training set in the class predictor algorithm. Secondly, designed as double blind test, the samples of external validation group were classified by the classify proteins/peptides patterns constructed by GA.

\section{Identification of protein markers}

Selected proteins/peptides were further purified using Nano Aquity UPLC C18 beads and serially eluted with $5 \%$ and $95 \%$ acetonitrile. These proteins/peptides were identified directly via LTQ Orbitrap XL (Michrom Bioresources, Auburn, USA) analysis in order to obtain the peptide sequences. For the Nano Ion Source, spray voltage was $1.8 \mathrm{kV}$, MS scan time was $60 \mathrm{~min}$, and the scanning range was $400-2000 \mathrm{~m} / \mathrm{z}$. Obitrap was used for the first scan (MS), with resolution of 100000 and LTQ was used for CID and the second scan (MS/MS). The 10 strongest ion intensities in the MS spectrum were selected as the parent ion for the MS/MS (single charge exclusion, not as a parent ion). The obtained chromatograms were analyzed with Bioworks Browser 3.3.1 SP1 
and the resulting mass lists were used for database search using Sequest ${ }^{\mathrm{Tw}}$ (IPI Human (3.45)).

\section{Detection of CEA}

The serum CEA of $36 \mathrm{CRC}$ and 35 health volunteers included in external validation group was detected using an electrochemiluminescent immunoassay method following the standard protocol by the manufacturer (The methods were omitted). The sample was diagnosed as CRC (CEA $\geq 5 \mathrm{ng} / \mathrm{ml})$, otherwise diagnosed as health volunteers $(\mathrm{CEA}<5 \mathrm{ng} / \mathrm{ml})$.

\section{Statistical methods, evaluation of assay precision}

We analyzed each spectrum obtained from MALDI-TOF MS with AutoflexAnalysis and ClinProt TM software (Bruker Daltonics), the former to detect the peak intensities of interest and the latter to compile the peaks across the spectrum obtained from all samples. This allowed differentiation between the cancer and healthy volunteers' samples. To evaluate the precision of the assay, we determined within- and between-run variations by use of multiple analyses of bead fractionation and MS for 2 plasma samples. For within- and between-run variation, we examined 3 peaks with various intensities. We determined within-run imprecision by evaluating the CVs for each sample, using 8 assays within a run, then determined between-run imprecision by performing 8 different assays over a period of 7 days. SPSS16.0 was used for analysis of the clinical characteristics of volunteers using $\chi^{2}$ test or $t$ test. The significance was set at $P<0.05$. Also, SPSS 16.0 was used to compare the diagnosis accuracy of the proteins/peptides models and CEA.

\section{Results}

System stability and experimental reproducibility were ensured through the use of 3 peaks with different molecular masses of standard serum

For the reproducibility of the protein profiling, withinand between-run reproducibility of 2 samples were determined with the WCX-MB fractionation and MALDITOF MS analysis. In each profile, 3 peaks with different molecular masses were selected to evaluate the precision of the assay. Despite varying proteins/peptides masses and spectrum intensities, the peak CVs were all $<5 \%$ in the within-run and $<10 \%$ in the between-run assays. These values were consistent with the reproducibility data for the Protein Biology System reported by the manufacturer (Bruker Daltonik).

\section{Differentiation of proteins/peptides selected out between} healthy volunteers and CRC

All healthy volunteers and CRC patients' sera proteins/peptides profiles were analyzed using a new high-resolution
MALDI-TOF MS coupled with bead fractionation. Samples were randomly distributed during processing and analysis. A total of 71 distinct $\mathrm{m} / \mathrm{z}$ values were resolved in the 600-20000 Da range (Figure 1). Differences in peak positions and intensities were observed and later used to statistically analyze the spectrum. ClinprotTools ver 2.2 (Bruker Daltonic) was used for peak detection. Twenty four proteins/peptides (including 9 up-regulated and 15 down-regulated peptides) displayed significant statistical significance $(\mathrm{P}<0.05)$ according to a Wilcoxon test between healthy volunteers and CRC patients groups. These data are shown in Table 2. Quantity analysis of these dysregulated proteins/peptides in CRCs showed that the expression levels were not correlated with the clinical characters of CRC, such as TNM stages, age, gender, et al.

\section{Establishment and validation of predicting model}

Classification models were developed to discriminate CRC from health volunteers. A GA in ClinProt was trained with the detected peaks from the discovery set to generate cross-validated classification models. Among the differentially expressed proteins/peptides, six $(\mathrm{m} / \mathrm{z}$ $1208,1467,1505,1618,1656$ and 4215) were chosen by the GA to build up a possible diagnostic cluster of signals. Regions of the mass spectrum obtained at about 800 resolving power measured are reported in Figure 2. The diagnostic capability of each peak determined by ROC curve is reported in Figure 3. Moreover areas of these peaks in the spectrum of CRC and healthy volunteers were statistically different from those of the healthy volunteers (Figure 4). Combination of the six peaks was provided as the best predicting model, achieving a recognition capacity of $98.25 \%$ (a sensitivity of $96.55 \%$ and a specificity of $100 \%$ ), with $20 \%$ of randomly selected data points omitted in the cross validation step. The accuracy of the models was verified with the validation set data, consisting of the $20 \%$ omitted samples. All the samples were correctly classified by the GA model (a sensitivity and a specificity of 100\%). Combination of two of these signals at $\mathrm{m} / \mathrm{z} 1505$ and 1618 differentiated the two populations (Figure 5).

To verify the accuracy of the established GA classification model, we introduced another group of samples (not used in model construction), which consisted of 36 $\mathrm{CRC}$ and 35 health volunteers. As a result, the model correctly classified $94.44 \%$ (34/36) of CRC (sensitivity) and $94.29 \%$ (33/35) of health volunteers (specificity), which surpassed that of CEA (a specificity of $52.78 \%$ $(19 / 36)$, and a sensitivity of $48.57 \%(17 / 35))$.

\section{Identification of markers}

With this bead-based proteomic technology, two of the potential markers at m/z 1505 and 1618 Da could distinguish CRC from healthy volunteers, which is beneficial 


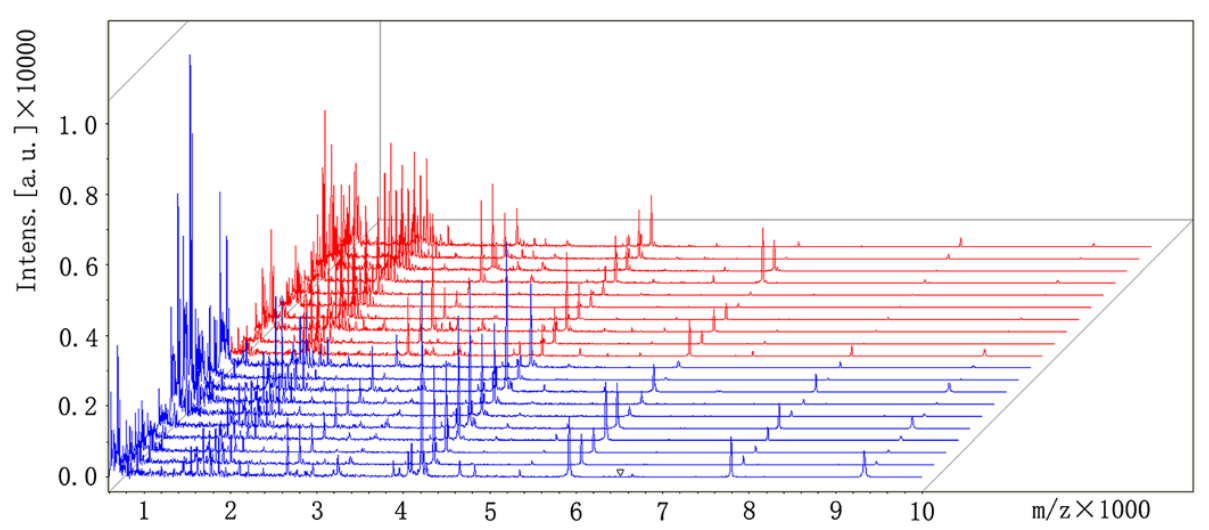

Figure 1 View of the aligned mass spectrum of the serum protein profile of model construction group obtained by MALDI-TOF after purification with WCX magnetic beads. Red represent 10 colorectal cancer patients, blue represent 10 healthy volunteers.

Table 2 Statistics of the $\mathbf{2 4}$ dysregulated proteins in colorectal cancer compared with health individuals

\begin{tabular}{|c|c|c|c|c|}
\hline Mass & $\begin{array}{c}\text { Colorectal cancer } \\
\quad \text { (Average } \pm \text { SD) }\end{array}$ & $\begin{array}{l}\text { Health volunteer } \\
\quad \text { (Average } \pm \text { SD) }\end{array}$ & $\begin{array}{l}\text { Regulation in } \\
\text { colorectal } \\
\text { cancer }\end{array}$ & P-value ${ }^{\star}$ \\
\hline $1618.52 ※$ & $64.84 \pm 37$ & $20.91 \pm 17.59$ & Up-regulation & 0.001 \\
\hline $1467.44 \%$ & $52 \pm 36.99$ & $12.41 \pm 6.73$ & Up-regulation & 0.000 \\
\hline $4214.69 ※$ & $45.08 \pm 24.84$ & $100.83 \pm 26.97$ & Down-regulation & 0.000 \\
\hline 798.20 & $41.9 \pm 26.18$ & $17.04 \pm 6.00$ & Up-regulation & 0.004 \\
\hline 825.73 & $25.51 \pm 16.96$ & $11.25 \pm 3.07$ & Up-regulation & 0.007 \\
\hline 651.55 & $16.05 \pm 15.27$ & $30.14 \pm 14.65$ & Down-regulation & 0.007 \\
\hline $1656.22 ※$ & $13.77 \pm 7.10$ & $4.69 \pm 2.63$ & Up-regulation & 0.000 \\
\hline 667.29 & $12.34 \pm 9.65$ & $19.76 \pm 8.55$ & Down-regulation & 0.028 \\
\hline $1505.47 ※$ & $10.81 \pm 5.89$ & $3.86 \pm 1.18$ & Up-regulation & 0.000 \\
\hline 1521.72 & $10.49 \pm 4.50$ & $5.20 \pm 2.38$ & Up-regulation & 0.002 \\
\hline $1208.30 ※$ & $10.39 \pm 4.48$ & $4.27 \pm 1.05$ & Up-regulation & 0.001 \\
\hline 1867.23 & $10.00 \pm 6.35$ & $17.64 \pm 7.03$ & Down-regulation & 0.018 \\
\hline 1585.25 & $9.64 \pm 3.93$ & $5.51 \pm 2.48$ & Up-regulation & 0.004 \\
\hline 4096.50 & $7.39 \pm 4.77$ & $14.26 \pm 3.80$ & Down-regulation & 0.005 \\
\hline 1780.03 & $6.90 \pm 5.09$ & $11.21 \pm 5.26$ & Down-regulation & 0.019 \\
\hline 7791.73 & $6.43 \pm 6.97$ & $13.01 \pm 3.03$ & Down-regulation & 0.014 \\
\hline 4058.71 & $3.59 \pm 2.73$ & $15.02 \pm 6.18$ & Down-regulation & 0.000 \\
\hline 4198.23 & $3.53 \pm 2.77$ & $7.44 \pm 2.62$ & Down-regulation & 0.003 \\
\hline 4271.61 & $2.04 \pm 1.71$ & $4.64 \pm 1.51$ & Down-regulation & 0.000 \\
\hline 4174.45 & $1.53 \pm 1.25$ & $2.63 \pm 1.07$ & Down-regulation & 0.021 \\
\hline 4177.42 & $1.50 \pm 1.25$ & $2.51 \pm 1.13$ & Down-regulation & 0.026 \\
\hline 4079.82 & $1.45 \pm 1.04$ & $2.49 \pm 0.91$ & Down-regulation & 0.014 \\
\hline 4076.90 & $1.43 \pm 1.04$ & $2.57 \pm 0.87$ & Down-regulation & 0.007 \\
\hline 3939.53 & $1.08 \pm 0.51$ & $1.88 \pm 0.68$ & Down-regulation & 0.005 \\
\hline
\end{tabular}

※The peptide selected for model construction.

$\triangle$ Peak area.

$\star P$ value calculated with the Wilcoxon test; values lower than 0.05 suggest statistical relevance. 


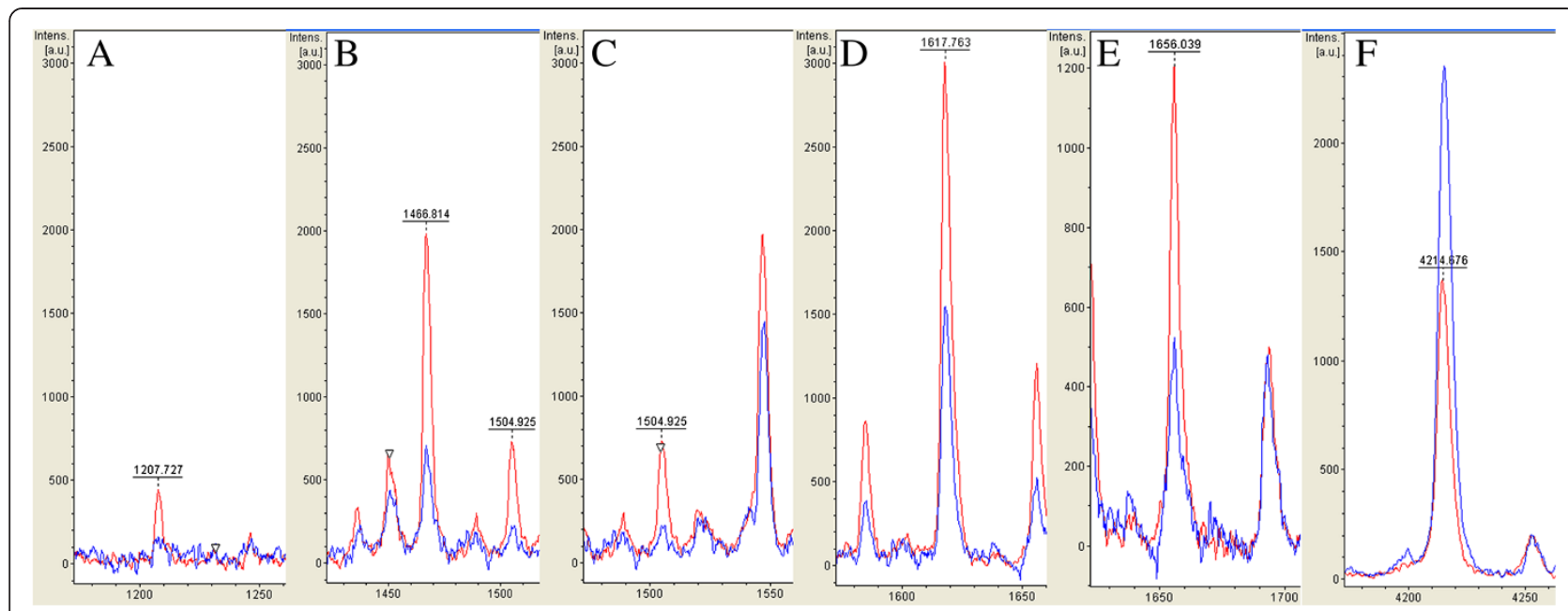

Figure 2 Zoom of the mass range for the six proteins (m/z 1208 (A), 1467 (B), 1505 (C), 1618 (D), 1656 (E) and 4215 (F), MALDI-TOF linear mode) used in the cluster to differentiate colorectal cancer (red) from healthy volunteers (blue).

for further purification and identification with relatively high peak intensity. With this in mind, these proteins/peptides could be potential markers for further immunoassay trials. After fractionation by Nano Aquity UPLC (Waters Corporation, Milford, USA), the eluted plasma samples were further purified by $\mathrm{C} 18$ beads with $5 \mu \mathrm{m}$ and $3.5 \mu \mathrm{m}$, then serially eluted with $5 \%$ and $95 \%$ acetonitrile. Samples were then subjected to LTQ Orbitrap XL MS/MS (Michrom Bioresources, Auburn, USA) analysis. The MS fingerprint was subjected to International Protein Index (IPI human v3.45 fasta with 71983 entries) searching for peptide sequence and further to NCBI database for protein identification. We had subsequently identified proteins by ion-spray mass spectrum. Mass spectrum with fragmentation pattern was identified through $\mathrm{b}$ and $\mathrm{y}$ ions which specify shown in Figure 6. Signal at $\mathrm{m} / \mathrm{z} 1505$ was identified as alpha-2-HS-glycoprotein precursor with the sequence G.VVSLGSPSGEVSHPR.K (IPI00022431.1 Gene_Symbol $=$ AHSG, $P=1.08 \times 10^{-5}$ ) and peak at $\mathrm{m} / \mathrm{z}$ 1618 was identified as tubulin beta chain with R.AILVDLE PGTMDSVR.S sequence (IPI00011654.2 Gene_Symbol = TUBB, $P=4.10 \times 10^{-5}$ ) (Figure $6 \mathrm{~A}$ and $\mathrm{B}$ ).

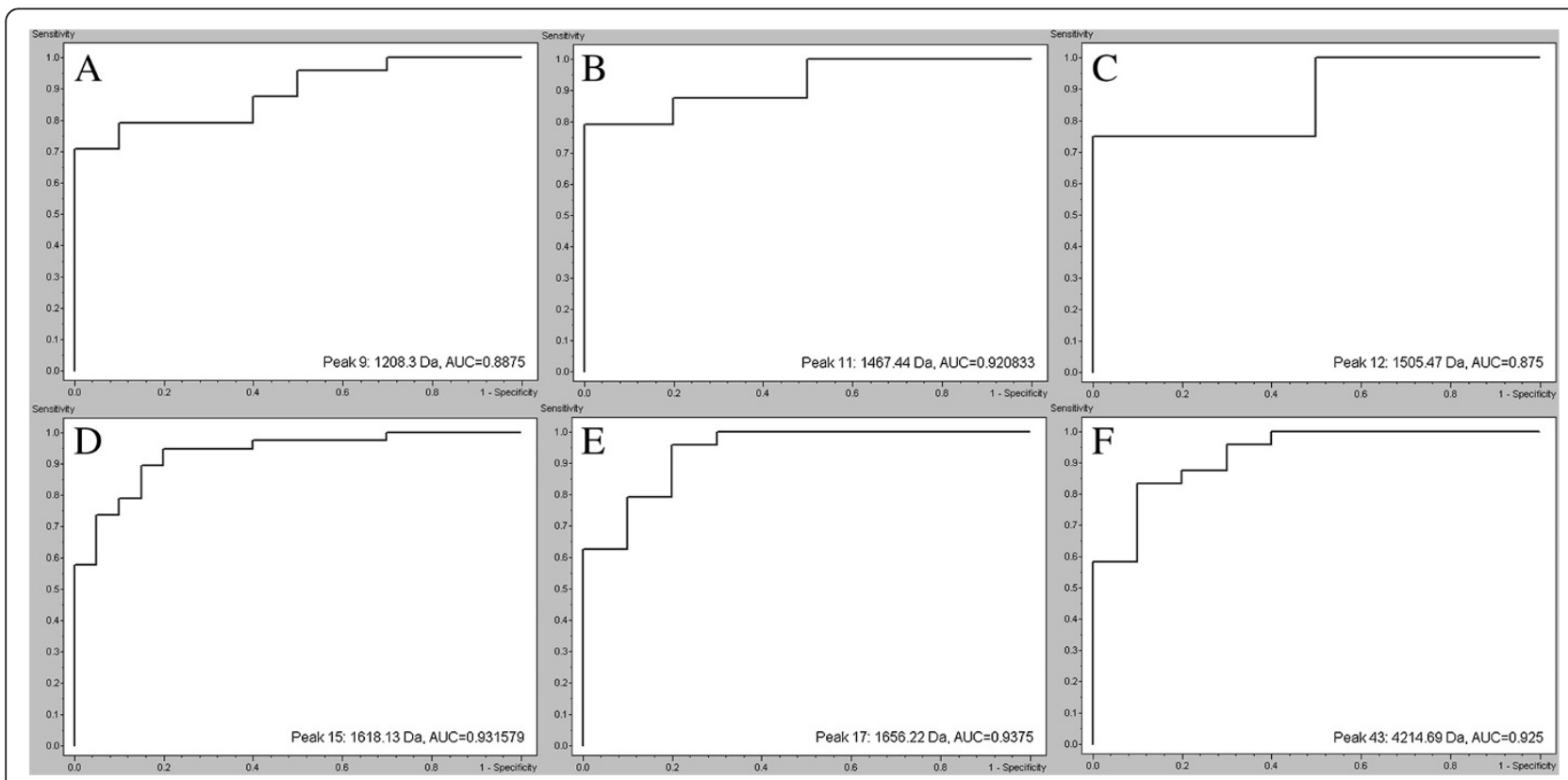

Figure 3 Receiver operating characteristic curve of the six proteins (m/z 1208 (A), 1467 (B), 1505 (C), 1618 (D), 1656 (E) and 4215 (F)) selected for the diagnostic model. AUC, Areas under the receiver operating characteristic curve. 


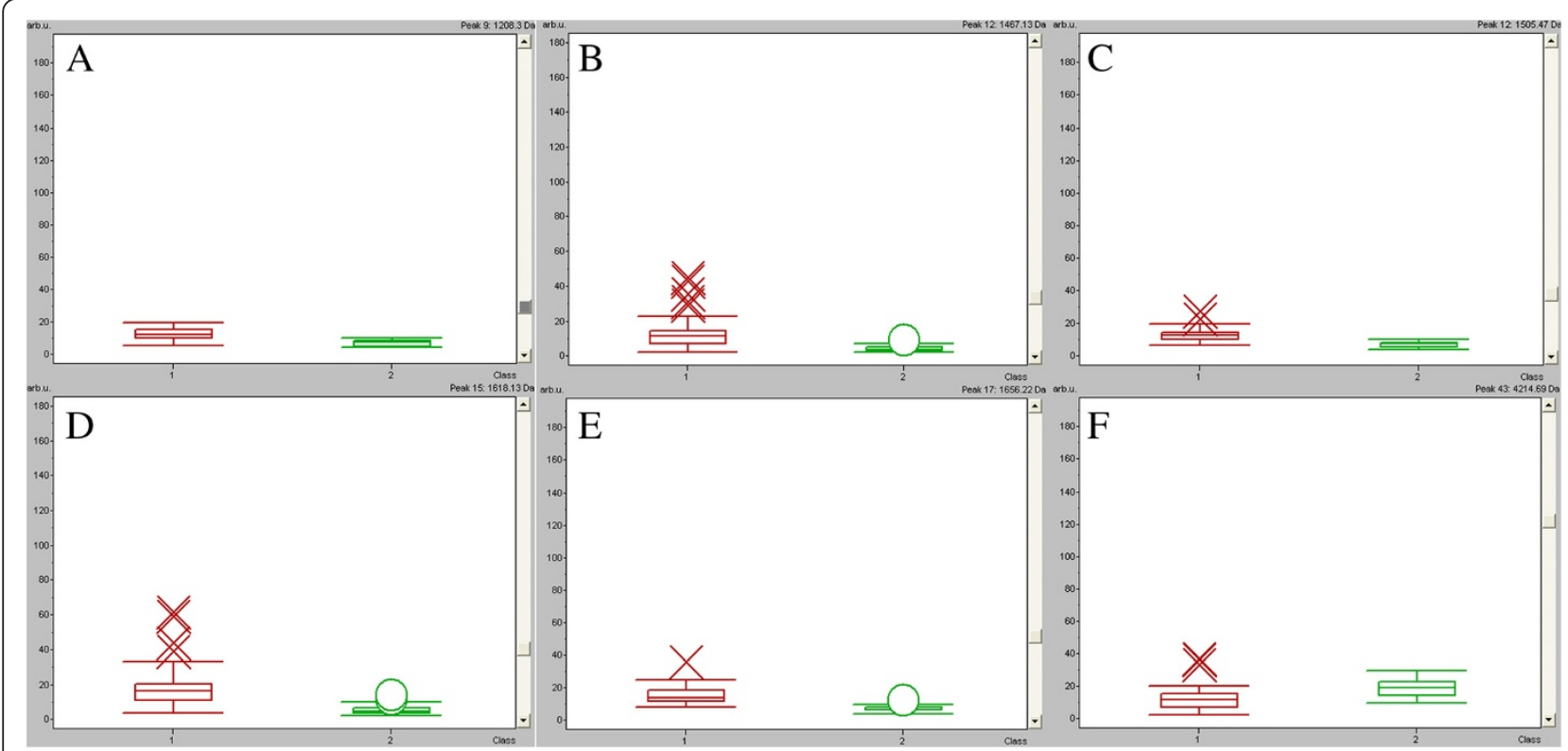

Figure 4 Box-and-whiskers plot calculated from the areas of the six proteins (m/z 1208 (A), 1467 (B), 1505 (C), 1618 (D), 1656 (E) and 4215 (F)) selected for the diagnostic model. Red represents colorectal cancer, Green represents healthy volunteers $(P<0.01$ versus ctrl).

\section{Discussion}

The usefulness of multiple markers for diagnosis, prognosis and for predicting the risk of developing diseases or their complications is now widely recognized [13,28-30]. Various proteomic approaches have been applied to biomarker discovery using biological fluids.

Regarding the search of biomarkers in CRC patients, several studies have been reported. The use of patient tissue samples allows comparison of the tumor sample with adjacent non-involved tissue. Alteration of 18 proteins was identified during tumor formation [31].

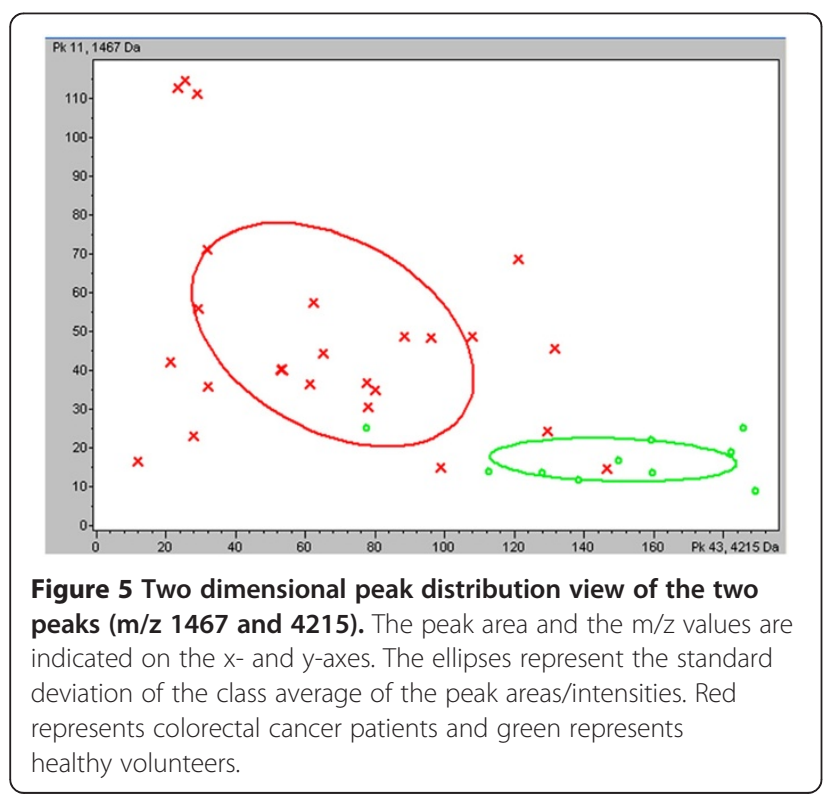

Several other comparative proteomic studies of human CRC and adjacent normal tissue identified more proteins that appear to change consistently among patients with CRC [32-35]. Previously, our group identified gelsolin protein down-regulated in CRC [36]. However, sample sizes are frequently limiting as priority has to be given to the use of surgically obtained tissue for conventional diagnosis [7].

Proteomic profiling is based upon the fact that proteins represent the dynamic state of the cells, reflecting earlier pathological and physiological changes in the disease more accurately than genomic sequencing [37]. Proteomic patterns should assist in the detection of tumor biomarkers, as well as in evaluating the efficacy of anticancer drugs. The comparison of sera of cancer patients and healthy volunteers provided peaks from three differentially detected proteins, complement component 3a des-Arg, alpha-1-antitrypsin and transferrin, with 95\% sensitivity and 91\% specificity [38]. Another SELDI study identified protein peaks that could distinguish CRC patients from normal subjects and classify patients with tumors at different stages, with $95 \%$ sensitivity and specificity [39]. Our group identified protein peaks that could different lymph node positive CRC patients from negative ones [17]. There has also been an effort to identify putative biomarkers in urine samples of CRC patients, with 19 protein peaks showing different intensities from those of healthy individuals ( $78 \%$ sensitivity, 87\% specificity) [40]. Further refinement and verification of these studies may eventually provide sets of clinically useful markers. Unfortunately, the proteome 


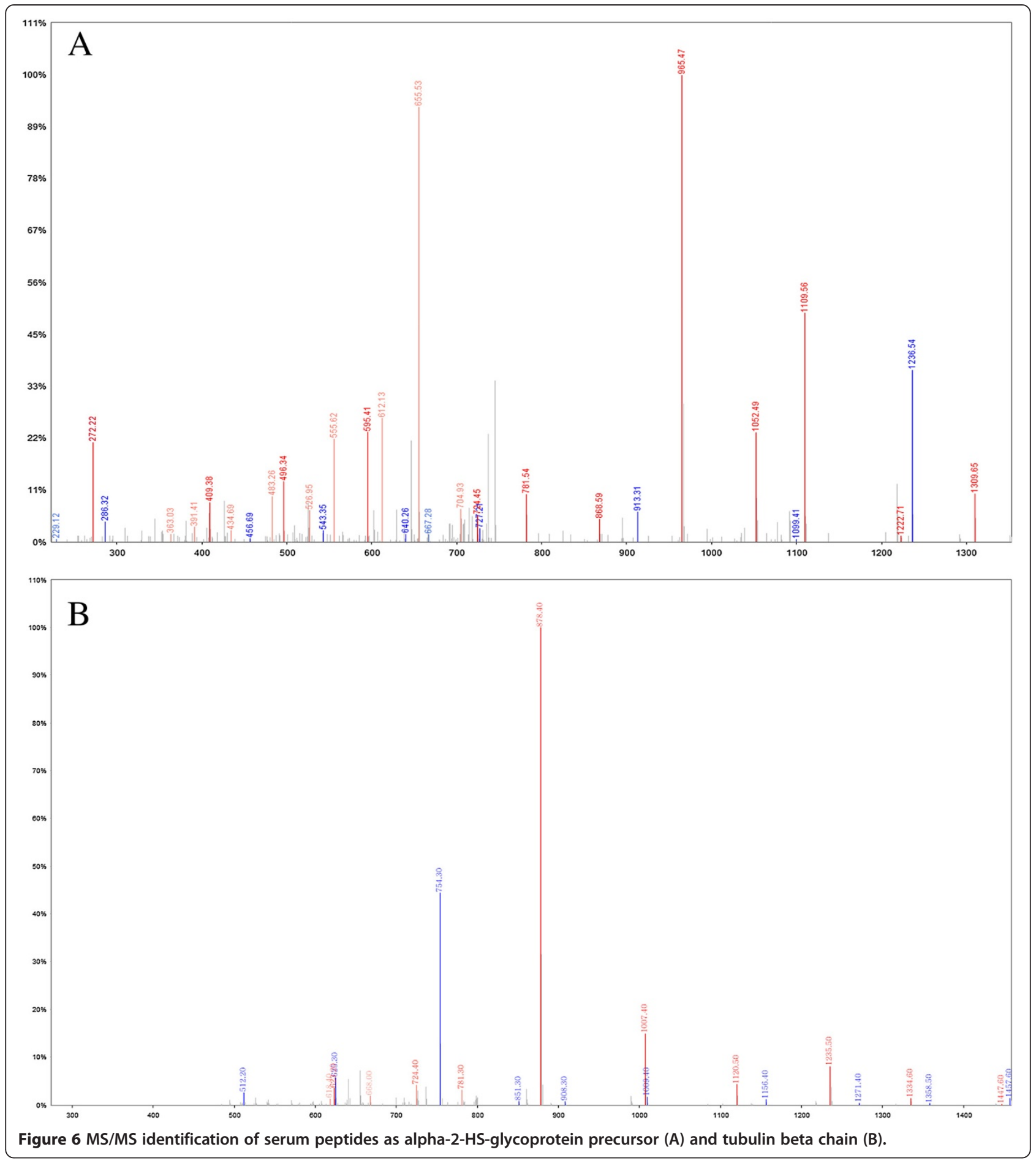

associated with CRC early diagnosis is currently poorly understood. Wang et al. identified two serum protein biomarkers (m/z 3961 and $5200 \mathrm{Da})$ for monitoring CRC [41]. Previously, an extensive proteomic analysis in the serum of patients with CRC was performed. A standardized serum preparation method for MALDITOF-MS was utilized based on WCX MB and was able to identify many valuable, low-abundance protein masses of interest [24]. However neither a characteristic protein cluster nor the structure identification of any of the proteins of the cluster was provided. Very recently it has been shown that clinical proteomic experiments can be still useful even when they deal with very small sample size [42]. 
In present study, a case control comparative analysis between $\mathrm{CRC}$ and health volunteers was performed by integrating the purification of proteins/peptides with WCX-MB, detection of peak intensity with MALDI-TOF MS, and profile analysis with ClinProt Tool software 2.2. Compared to controls, CRC shares 24 significantly differentiated proteins/peptides, including 9 up-regulated and 15 down-regulated peptides. By using the GA analysis, a cluster of 6 peptides at $\mathrm{m} / \mathrm{z} 1208,1467,1505$, 1618, 1656 and 4215 were developed as a classification mode, achieved a recognition capacity and a crossvalidation of close to $100 \%$ to discriminate CRC from health volunteers. Also the classification mode could correctly classify CRC from health volunteers in blinded verification test, which surpass that of CEA.

The diagnostic capability of each peak at $\mathrm{m} / \mathrm{z} 1208$, $1467,1505,1618,1656$ and 4215 determined by ROC curve shows to be a highly accurate test (AUC > 0.88) [43]. These protein/peptide fragments with high specificity and sensitivity may be good serum biomarkers for CRC. Later studies in a larger population group are necessary to confirm this finding. Further evaluation identified the 1505 and 1618 Da marker as alpha-2-HS-glycoprotein precursor and tubulin beta chain, respectively by LTQ Obitrap XL.

Alpha-2-HS-glycoprotein precursor, a single chain form of alpha-2-HS-glycoprotein, is converged into the two chain form after the completion of carbohydrate sidechain processing [44]. Human serum protein alpha -2-HS glycoprotein is the human species homologue of bovine fetuin-A [45]. Alpha-2-HS-glycoprotein is a circulating plasma glycoprotein, produced abundantly during fetal development by multiple tissues, whereas in the adult, it is produced predominantly by the liver [46]. A number of studies suggest that alpha-2-HS-glycoprotein is a multifunctional protein [47]. Difference expression of alpha-2-HS-glycoprotein exists in breast cancer, CRC, lung cancer, liver cancer, head and neck cancer [48-54]. As for CRC, serum alpha-2-HS-glycoprotein inhibits tumor progression by blocking transforming growth factor- $\beta 1$ (TGF- $\beta 1$ ) binding to cell surface receptors, suppressing TGF- $\beta$ signal transduction, and inhibiting TGF- $\beta$-induced epithelial-mesenchymal transition [55]. Familial adenomatous polyposis (FAP) is one of the most important clinical hereditary forms of inherited susceptibility to CRC and is characterized by a high degree of phenotypic heterogeneity. Alpha -2-HS-glycoprotein was down-regulated in carpeting versus diffuse FAP patients and healthy donors, which was identified as serum molecule differently expressed in FAP patients [56]. Increasing chronological age is a risk factor for many types of cancer including colorectal. An understanding of the biology of aging and factors which regulate it may provide insight into cancer pathogenesis.
Maxwell $\mathrm{F}$ et al. identified that decreasing alpha-2-HSglycoprotein concentration was associated with increasing chronological age, which indicates accelerated biological aging. Furthermore, alpha-2-HS-glycoprotein levels can be used to distinguish between colon and rectal cancers [50]. However, serum alpha-2-HS-glycoprotein level was found not to be significantly changed by an ELISA test in CRC by another group [51]. Presently, up-regulated alpha-2-HS-glycoprotein precursor was determined in CRC, which may perform as a diagnosis marker for CRC.

Tubulin, the subunit protein of microtubules, has generally been thought to be exclusively a cytoplasmic protein in higher eukaryotes. It's an important target for anti-tumor drugs [57]. Structurally, tubulin is an $\alpha / \beta$ heterodimer [58]. Abnormal expression of the specific $\beta$-tubulin isotype is related to resistance to chemotherapy in solid cancers [59-61]. This marker may assume a greater role in therapeutic decision making. However, overexpression of subtypes of $\beta$-tubulin, class III $\beta$-tubulin and class VI $\beta$-tubulin, is a purely prognostic factor related to biologic aggressiveness of CRC, surprisingly this phenomenon is restricted to female patients [62]. Early detection of malignancies of the gastrointestinal tract can lead to improved survival of patients worldwide. Beta-tubulin is a cancer-specific antigen in patients with CRC and other gastrointestinal malignancies, including gastric cancer, esophageal cancer and pancreatic cancer. Sensitivities ranged between 20\% and $40 \%$ for various cancers with a specificity of $96 \%$ [63]. We identified that $\beta$-tubulin up-regulated in CRC, which show great potential for diagnosis for CRC.

In conclusion, this study is one of the few study to screen CRC related proteins/peptides in sera by combining WCX-MB and MALDI-TOF-MS according to our knowledge. The classification model we have set up have application in providing alternatives for CRC diagnosis, and the up-regulated alpha-2-HS-glycoprotein precursor and $\beta$-tubulin provide a better understanding of the pathogenesis in CRC or help in tailoring the use of chemotherapy to each patient, finally resulting in an improvement in patient outcome. Continuing research into the underlying pathophysiology of CRC will ultimately lead to more effective and better-tolerated therapies. Additional analysis of a larger set of individual samples in combination with more traditional immunoassays such as ELISA are required to further confirm whether high level of serum alpha-2-HS-glycoprotein precursor and $\beta$-tubulin increased odds ratios (ORs) of CRC in a nested case-control sample of CRC individuals such as those observed in this study.

\section{Competing interests}

The authors stated that there are no conflicts of interest regarding the publication of this article. 


\section{Authors' contribution}

NF carried out the mass spectrometry analysis, bioinformatics and statistical analysis, and drafted the manuscript. RK, XG and ML carried out the sample collection and purification. $\quad H C$ and $Y L$ carried out the identification of markers and CEA detection. CG participated in the design of the study. All authors read and approved the final manuscript.

\section{Acknowledgments}

The authors gratefully acknowledge the assistance of Dr. Yan Li of Fanxing BioTech for her expertise in protein identification.

\section{Author details \\ ${ }^{1}$ Institute of Anal-colorectal Surgery, No.150 Central Hospital of PLA, Luoyang, RP China. ${ }^{2}$ The General Hospital of Jinan Military Region, Jinan, China. ${ }^{3}$ Respiration Department, No.150 Central Hospital of PLA, Luoyang, RP China. ${ }^{4}$ Neuro- Surgery Department, No.150 Central Hospital of PLA, Luoyang, RP China. ${ }^{5}$ Clinical Laboratory, The First People's Hospital of the City of Luoyang, Luoyang, RP China.}

Received: 23 September 2013 Accepted: 5 March 2014

Published: 12 March 2014

\section{References}

1. Jemal A, Bray F, Center MM, Ferlay J, Ward E, Forman D: Global cancer statistics. CA Cancer J Clin 2011, 61:69-90.

2. Jemal A, Siegel $R, X u$ J, Ward E: Cancer statistics, 2010. CA Cancer J Clin 2010, 60:277-300

3. Ciccolallo L, Capocaccia R, Coleman MP, Berrino F, Coebergh JW, Damhuis RA, Faivre J, Martinez-Garcia C, Moller H, Ponz de Leon M, Launoy G, Raverdy N, Williams EM, Gatta G: Survival differences between European and US patients with colorectal cancer: role of stage at diagnosis and surgery. Gut 2005, 54:268-273.

4. Engwegen JY, Helgason HH, Cats A, Harris N, Bonfrer JM, Schellens JH, Beijnen $\mathrm{JH}$ : Identification of serum proteins discriminating colorectal cancer patients and healthy controls using surface-enhanced laser desorption ionisation-time of flight mass spectrometry. World J Gastroenterol 2006, 12:1536-1544

5. Edwards BK, Ward E, Kohler BA, Eheman C, Zauber AG, Anderson RN, Jemal A Schymura MJ, Lansdorp-Vogelaar I, Seeff LC, Van Ballegooijen M, Goede SL, Ries LA: Annual report to the nation on the status of cancer, 1975-2006, featuring colorectal cancer trends and impact of interventions (risk factors, screening, and treatment) to reduce future rates. Cancer 2010, 116:544-573.

6. Smith RA, Cokkinides V, Brooks D, Saslow D, Shah M, Brawley OW: Cancer screening in the United States, 2011: A review of current American Cancer Society guidelines and issues in cancer screening. CA Cancer J Clin 2011, 61:8-30

7. Ang CS, Phung J, Nice EC: The discovery and validation of colorectal cancer biomarkers. Biomed Chromatogr 2011, 25:82-99.

8. Ahlquist DA: Molecular detection of colorectal neoplasia. Gastroenterology 2010, 138:2127-2139.

9. Yatabe J, Yatabe MS, Ishibashi K, Nozawa Y, Sanada H: Early detection of colon cancer by amino acid profiling using Aminolndex technology: a case report. Diagn Pathol 2013, 8:203.

10. Chen C, Wang L, Liao Q, Huang Y, Ye H, Chen F, Xu L, Ye M, Duan S: Hypermethylation of EDNRB promoter contributes to the risk of colorectal cancer. Diagn Pathol 2013, 8:199.

11. Fletcher RH: Carcinoembryonic antigen. Ann Intern Med 1986, 104:66-73.

12. Wulfkuhle JD, Liotta LA, Petricoin EF: Proteomic applications for the early detection of cancer. Nat Rev Cancer 2003, 3:267-275.

13. Issaq HJ, Xiao Z, Veenstra TD: Serum and plasma proteomics. Chem Rev 2007, 107:3601-3620.

14. Pan C, He N, Zhao M, Gu Y, Huang Z, Li W, Xia Y, Wu P: Subdividing the M1 stage of liver metastasis for nasopharyngeal carcinoma to better predict metastatic survival. Med Oncol 2011, 28:1349-1355.

15. Fan NJ, Gao CF, Zhao G, Wang XL, Qiao L: Serum peptidome patterns for early screening of esophageal squamous cell carcinoma. Biotechnol Appl Biochem 2012, 59:276-282.

16. Fan NJ, Gao CF, Zhao G, Wang XL, Liu QY: Serum peptidome patterns of breast cancer based on magnetic bead separation and mass spectrometry analysis. Diagn Pathol 2012, 7:45.
17. Fan NJ, Gao CF, Wang XL: Identification of regional lymph node involvement of colorectal cancer by serum SELDI proteomic patterns. Gastroenterol Res Pract 2011, 2011:784967.

18. West-Norager M, Kelstrup CD, Schou C, Hogdall EV, Hogdall CK, Heegaard $\mathrm{NH}$ : Unravelling in vitro variables of major importance for the outcome of mass spectrometry-based serum proteomics. J Chromatogr B Analyt Technol Biomed Life Sci 2007, 847:30-37.

19. Shin S, Cazares L, Schneider H, Mitchell S, Laronga C, Semmes OJ, Perry RR Drake RR: Serum biomarkers to differentiate benign and malignant mammographic lesions. J Am Coll Surg 2007, 204:1065-1071. discussion 1071-1063.

20. Baumann S, Ceglarek U, Fiedler GM, Lembcke J, Leichtle A, Thiery J: Standardized approach to proteome profiling of human serum based on magnetic bead separation and matrix-assisted laser desorption/ ionization time-of-flight mass spectrometry. Clin Chem 2005, 51:973-980.

21. Huang YJ, Xuan C, Zhang BB, Liao M, Deng KF, He M, Zhao JM: SELDI-TOF MS profiling of serum for detection of nasopharyngeal carcinoma. J Exp Clin Cancer Res 2009, 28:85

22. Yao N, Chen H, Lin H, Deng C, Zhang X: Enrichment of peptides in serum by $\mathrm{C}(8)$-functionalized magnetic nanoparticles for direct matrix-assisted laser desorption/ionization time-of-flight mass spectrometry analysis. J Chromatogr A 2008, 1185:93-101.

23. Whiteaker JR, Zhao L, Zhang HY, Feng LC, Piening BD, Anderson L, Paulovich AG: Antibody-based enrichment of peptides on magnetic beads for mass-spectrometry-based quantification of serum biomarkers. Anal Biochem 2007, 362:44-54.

24. Fan NJ, Gao CF, Wang XL, Zhao G, Liu QY, Zhang YY, Cheng BG: Serum peptidome patterns of colorectal cancer based on magnetic bead separation and maldi-tof mass spectrometry analysis. J Biomed Biotechnol 2012, 2012:985020.

25. Tang W, Shi YQ, Zou JJ, Chen XF, Zheng JY, Zhao SW, Liu ZM: Serum biomarker of diabetic peripheral neuropathy indentified by differential proteomics. Front Biosci 2011, 16:2671-2681.

26. Compton CC, Greene FL: The staging of colorectal cancer: 2004 and beyond. CA Cancer J Clin 2004, 54:295-308.

27. Ketterlinus $\mathrm{R}$, Hsieh SY, Teng SH, Lee H, Pusch W: Fishing for biomarkers: analyzing mass spectrometry data with the new ClinProTools software. Biotechniques 2005, suppl:37-40.

28. Zethelius B, Berglund L, Sundstrom J, Ingelsson E, Basu S, Larsson A, Venge $P$, Arnlov J: Use of multiple biomarkers to improve the prediction of death from cardiovascular causes. N Engl J Med 2008, 358:2107-2116.

29. Liu Y, Tang W, Wang J, Xie L, Li T, He Y, Qin X, Li S: Clinicopathological and prognostic significance of S100A4 overexpression in colorectal cancer: a meta-analysis. Diagn Pathol 2013, 8:181.

30. Wangefjord S, Brandstedt J, Lindquist KE, Nodin B, Jirstrom K, Eberhard J: Associations of beta-catenin alterations and MSI screening status with expression of key cell cycle regulating proteins and survival from colorectal cancer. Diagn Pathol 2013, 8:10

31. Stulik J, Hernychova L, Porkertova S, Knizek J, Macela A, Bures J, Jandik P, Langridge Jl, Jungblut PR: Proteome study of colorectal carcinogenesis. Electrophoresis 2001, 22:3019-3025.

32. Rho JH, Qin S, Wang JY, Roehrl MH: Proteomic expression analysis of surgical human colorectal cancer tissues: up-regulation of PSB7, PRDX1, and SRP9 and hypoxic adaptation in cancer. J Proteome Res 2008, 7:2959-2972.

33. Alfonso P, Nunez A, Madoz-Gurpide J, Lombardia L, Sanchez L, Casal Jl: Proteomic expression analysis of colorectal cancer by two-dimensional differential gel electrophoresis. Proteomics 2005, 5:2602-2611.

34. Kim HJ, Kang HJ, Lee H, Lee ST, Yu MH, Kim H, Lee C: Identification of S100A8 and S100A9 as serological markers for colorectal cancer. J Proteome Res 2009, 8:1368-1379.

35. Friedman DB, Hill S, Keller JW, Merchant NB, Levy SE, Coffey RJ, Caprioli RM: Proteome analysis of human colon cancer by two-dimensional difference gel electrophoresis and mass spectrometry. Proteomics 2004, 4:793-811.

36. Fan NJ, Gao CF, Wang CS, LV JJ, Zhao G, Sheng XH, Wang XL, Li DH, Liu QY, Yin J: Discovery and verification of gelsolin as a potential biomarker of colorectal adenocarcinoma in the Chinese population: examining differential protein expression using an iTRAQ labelling-based proteomics approach. Can J Gastroenterol 2012, 26:41-47.

37. Hudler P, Gorsic M, Komel R: Proteomic strategies and challenges in tumor metastasis research. Clin Exp Metastasis 2010, 27:441-451. 
38. Ward DG, Suggett $N$, Cheng $Y$, Wei $W$, Johnson $H$, Billingham $L$, Ismail T, Wakelam MJ, Johnson PJ, Martin A: Identification of serum biomarkers for colon cancer by proteomic analysis. Br J Cancer 2006, 94:1898-1905.

39. Liu XP, Shen J, Li ZF, Yan L, Gu J: A serum proteomic pattern for the detection of colorectal adenocarcinoma using surface enhanced laser desorption and ionization mass spectrometry. Cancer Invest 2006 24:747-753

40. Ward DG, Nyangoma S, Joy H, Hamilton E, Wei W, Tselepis C, Steven N, Wakelam MJ, Johnson PJ, Ismail T, Martin A: Proteomic profiling of urine for the detection of colon cancer. Proc Natl Acad Sci U S A 2008, 6:19.

41. Wang Q, Shen J, Li ZF, Jie JZ, Wang WY, Wang J, Zhang ZT, Li ZX, Yan L, Gu J: Limitations in SELDI-TOF MS whole serum proteomic profiling with IMAC surface to specifically detect colorectal cancer. BMC Cancer 2009, 9:287.

42. Cairns DA, Barrett JH, Billingham LJ, Stanley AJ, Xinarianos G, Field JK, Johnson PJ, Selby PJ, Banks RE: Sample size determination in clinical proteomic profiling experiments using mass spectrometry for class comparison. Proteomics 2009, 9:74-86.

43. Swets JA: Measuring the accuracy of diagnostic systems. Science 1988, 240:1285-1293.

44. Kornfeld R, Kornfeld S: Assembly of asparagine-linked oligosaccharides. Annu Rev Biochem 1985, 54:631-664.

45. Denecke B, Graber S, Schafer C, Heiss A, Woltje M, Jahnen-Dechent W: Tissue distribution and activity testing suggest a similar but not identical function of fetuin-B and fetuin-A. Biochem J 2003, 376:135-145.

46. Triffitt JT, Gebauer U, Ashton BA, Owen ME, Reynolds JJ: Origin of plasma alpha2HS-glycoprotein and its accumulation in bone. Nature 1976, 262:226-227.

47. Reynolds JL, Skepper JN, McNair R, Kasama T, Gupta K, Weissberg PL, Jahnen-Dechent W, Shanahan CM: Multifunctional roles for serum protein fetuin-a in inhibition of human vascular smooth muscle cell calcification. J Am Soc Nephrol 2005, 16:2920-2930.

48. Sakwe AM, Koumangoye R, Goodwin SJ, Ochieng J: Fetuin-A (\{alpha\}2HSglycoprotein) is a major serum adhesive protein that mediates growth signaling in breast tumor cells. J Biol Chem 2010, 285:41827-41835.

49. Yi JK, Chang JW, Han W, Lee JW, Ko E, Kim DH, Bae JY, Yu J, Lee C, Yu MH, Noh DY: Autoantibody to tumor antigen, alpha 2-HS glycoprotein: a novel biomarker of breast cancer screening and diagnosis. Cancer Epidemiol Biomarkers Prev 2009, 18:1357-1364.

50. Maxwell F, McGlynn LM, Muir HC, Talwar D, Benzeval M, Robertson T, Roxburgh CS, McMillan DC, Horgan PG, Shiels PG: Telomere attrition and decreased fetuin-A levels indicate accelerated biological aging and are implicated in the pathogenesis of colorectal cancer. Clin Cancer Res 2011, 17:5573-5581.

51. Dowling P, Clarke C, Hennessy K, Torralbo-Lopez B, Ballot J, Crown J, Kiernan I, O'Byrne KJ, Kennedy MJ, Lynch V, Clynes M: Analysis of acute-phase proteins, AHSG, C3, CLI, HP and SAA, reveals distinctive expression patterns associated with breast, colorectal and lung cancer. Int J Cancer 2012, 131:911-923.

52. Cottingham K: Candidate biomarkers for liver cancer. J Proteome Res 2009, 8:428.

53. Comunale MA, Wang M, Hafner J, Krakover J, Rodemich L, Kopenhaver B, Long RE, Junaidi O, Bisceglie AM, Block TM, Mehta AS: Identification and development of fucosylated glycoproteins as biomarkers of primary hepatocellular carcinoma. J Proteome Res 2009, 8:595-602.

54. Suarez Nieto C, Cuesta Garcia A, Fernandez Bustillo E, Mendez Colunga JC, Alvarez Marcos C: Serum glycoproteins and prognosis in cancer of the head and neck. Clin Otolaryngol Allied Sci 1986, 11:41-45.

55. Swallow CJ, Partridge EA, Macmillan JC, Tajirian T, DiGuglielmo GM, Hay K, Szweras M, Jahnen-Dechent W, Wrana JL, Redston M, Gallinger S, Dennis $\mathrm{JW}$ : alpha2HS-glycoprotein, an antagonist of transforming growth factor beta in vivo, inhibits intestinal tumor progression. Cancer Res 2004, 64:6402-6409.

56. Quaresima B, Crugliano T, Gaspari M, Faniello MC, Cosimo P, Valanzano R, Genuardi M, Cannataro M, Veltri P, Baudi F, Doldo P, Cuda G, Venuta S, Costanzo F: A proteomics approach to identify changes in protein profiles in serum of Familial Adenomatous Polyposis patients. Cancer Lett 2008, 272:40-52.

57. Yeh IT, Luduena RF: The betall isotype of tubulin is present in the cell nuclei of a variety of cancers. Cell Motil Cytoskeleton 2004, 57:96-106.
58. Bryan J, Wilson L: Are cytoplasmic microtubules heteropolymers? Proc Natl Acad Sci U S A 1971, 68:1762-1766.

59. Perez EA: Microtubule inhibitors: differentiating tubulin-inhibiting agents based on mechanisms of action, clinical activity, and resistance. $\mathrm{Mol}$ Cancer Ther 2009, 8:2086-2095.

60. Dumontet $C$, Jordan MA: Microtubule-binding agents: a dynamic field of cancer therapeutics. Nat Rev Drug Discov 2010, 9:790-803.

61. Kavallaris M: Microtubules and resistance to tubulin-binding agents. Nat Rev Cancer 2010, 10:194-204.

62. Mariani M, Zannoni GF, Sioletic S, Sieber S, Martino C, Martinelli E, Coco C, Scambia G, Shahabi S, Ferlini C: Gender influences the class III and V beta-tubulin ability to predict poor outcome in colorectal cancer. Clin Cancer Res 2012, 18:2964-2975.

63. Bouras G, Nakanishi T, Fujita Y, Tsunemi S, Takubo T, Tanigawa N: Identification of beta-tubulin as a common immunogen in gastrointestinal malignancy by mass spectrometry of colorectal cancer proteome: implications for early disease detection. Anal Bioanal Chem 2012, 403:1801-1809.

doi:10.1186/1746-1596-9-53

Cite this article as: Fan et al:: Identification alpha-2-HS-glycoprotein precursor and tubulin beta chain as serology diagnosis biomarker of colorectal cancer. Diagnostic Pathology 2014 9:53.

\section{Submit your next manuscript to BioMed Central and take full advantage of:}

- Convenient online submission

- Thorough peer review

- No space constraints or color figure charges

- Immediate publication on acceptance

- Inclusion in PubMed, CAS, Scopus and Google Scholar

- Research which is freely available for redistribution 